\title{
Modelagem do efeito da temperatura na secagem de licuri (Syagrus coronata)
}

\author{
Ana Cleide Nascimento dos Santos ${ }^{1}$; Pablo Rodrigo Fica Piras ${ }^{2}$; \\ 1. Bolsista PIBIC/FAPESB, graduanda em Engenharia de Alimentos, Universidade Estadual de Feira de Santana \\ (UEFS), cleidekeusantos@gmail.com \\ 2. Orientador, professor do Departamento de Tecnologia, tutor do PET Engenharias, UEFS, pafipi@uefs.br
}

PALAVRAS-CHAVE: cinética secagem, razão de umidade, modelagem logarítmica.

\section{INTRODUÇÃO}

O Licuri (Syagrus coronata) é uma palmeira nativa do território brasileiro. É nativa de uma região que compreende o sul de Pernambuco, os estados de Alagoas e Sergipe, toda a região central, oriental e sul da Bahia e toda a região norte de Minas Gerais, preferência característica por regiões secas e áridas da Caatinga (NOBLICK, 1986).

Otimizar o uso desta palmeira contribui para a melhoria da qualidade de vida da população dessa região, tanto com a utilização dos seus frutos na alimentação humana, pois estes apresentam um bom valor nutricional, como também para aumentar o desenvolvimento socioeconômico do semiárido, gerando renda para a população, pela utilização do óleo de suas amêndoas como matéria prima para diversos produtos (SANTOS, 2011).

A secagem é um processo físico caracterizado pela remoção de uma substância volátil, em geral a água, a partir de um material sólido. A porção de água contida no sólido qualquer proporciona a redução do volume e peso, facilitando o armazenamento e transporte, agregando valor (MENEZES et al., 2013).

Secagem é um método bem estabelecido de conservação de alimentos, que promove a conservação das propriedades físicas e químicas durante um longo período de tempo, desde que os baixos níveis de água no sólido seco impeçam a ação enzimática e também evitem o crescimento de microrganismos. No entanto, a exposição dos materiais à secagem com ar quente pode causar a degradação deles. As variáveis-chave no processo de secagem são o tempo de secagem, temperatura e atividade de água inicial e final. Seus valores são determinantes para a qualidade do produto final (MOCELIN, et al., 2014).

Este trabalho propõe a verificação da influência da temperatura sobre a secagem da amêndoa do licuri.

\section{Metodologia}

As amêndoas de licuri (Syagrus coronata) foram adquiridas na região de Capim Grosso - Bahia.

Os frutos foram levados para os laboratórios de Engenharia Bioquímica e de Química de Alimentos, no Labotec 2, do Departamento de Tecnologia da Universidade Estadual de Feira de Santana.

Previamente à secagem, as amêndoas do licuri foram submetidas a seleção, tratamento e segregação. Foram selecionadas as amostras do mesmo formato com tamanhos equivalentes, em seguida, foram divididas em bandas. Para a secagem, as 
amostras foram preparadas baseando-se em uma porção de 5 gramas por cadinho de porcelana.

A secagem de cada amostra (5 g) foi realizada em uma estufa com circulação forçada de ar (Nova Ética) em temperaturas 60,70 e $80^{\circ} \mathrm{C}$, sem interrupção da secagem até se atingir o equilíbrio. Todas as análises foram feitas em triplicata.

As amostras para cada temperatura foram monitoradas a cada 1 hora pela pesagem em balança analítica (modelo Ay 220) com uma precisão de 0,001g. Após a secagem, as amostras foram mantidas no dessecador, a fim de obter o peso seco.

\section{Análise e discussão dos resultados}

A partir dos dados obtidos da secagem, foi possível construir três gráficos com as temperaturas utilizadas, que apresentaram a diminuição do teor de água das amêndoas do licuri em relação à evolução do tempo durante a secagem.

Figura 1: Secagem a temperatura a $60^{\circ} \mathrm{C}$. Representando o comportamento do teor de água das amêndoas do licuri em função do tempo.

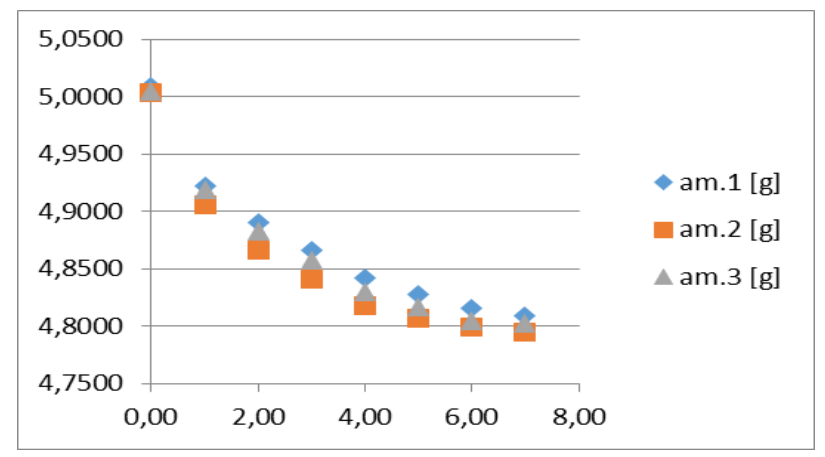

Figura 2: Secagem a temperatura a $70^{\circ} \mathrm{C}$. Representando o comportamento do teor de água das amêndoas do licuri em função do tempo.

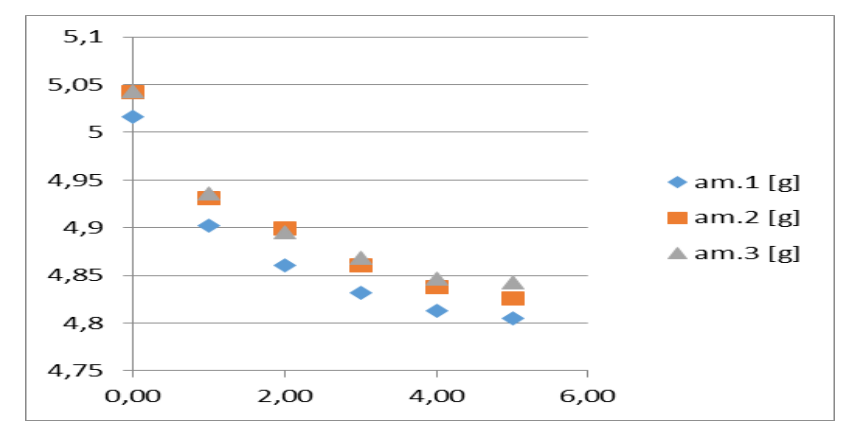

Figura 3: Secagem a temperatura a $80^{\circ} \mathrm{C}$. Representando o comportamento do teor de água das amêndoas do licuri em função do tempo.

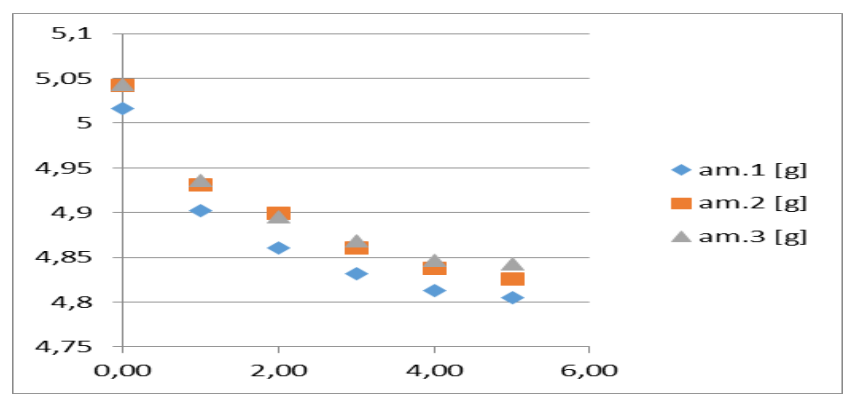


Embora tenha sido monitorado por um tempo mais longo a umidade equivalente na operação a $60^{\circ} \mathrm{C}, 7$ horas, os dados de cada operação realizada em temperaturas diferentes não permitem confirmar uma influência marcada da temperatura na cinética da operação de secagem. Quando graficam-se conjuntamente as médias obtidas para cada temperatura, obtém-se o apresentado na Figura 4.

Figura 4: Secagem a três temperaturas $\left(60,70\right.$ e $\left.80^{\circ} \mathrm{C}\right)$, teor de água das amêndoas do licuri em função do tempo.

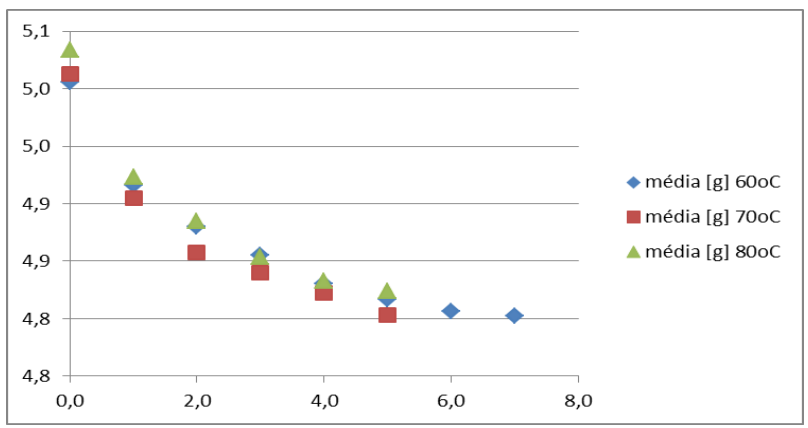

Foi aplicada a modelagem cinética à secagem, e o modelo que mais se aproximou dos dados obtidos nas bateladas de secagem foi o ajuste logarítmico, tanto para o parâmetro Mt (umidade no tempo t) quanto para o parâmetro MR (razão de umidade):

$$
\begin{aligned}
& M_{t}=a_{1} \cdot \ln (t)+b_{1} \\
& M R=a_{2} \cdot \ln (t)+b_{2}
\end{aligned}
$$

$\mathrm{O}$ ajuste para cada sequência de médias de cinéticas de secagem a diferentes temperaturas está representado nas Figuras 5 (para Mt) e 6 (para MR)

Figura 5: Ajuste logarítmico da média de massas Mt vs. t, para diferentes temperaturas

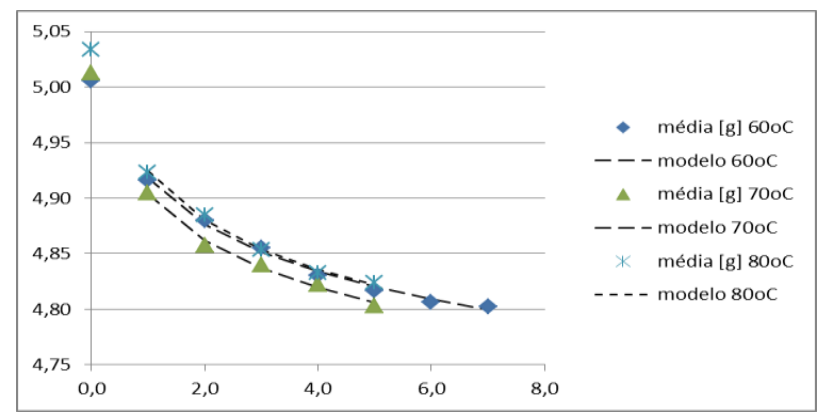

Figura 6: Ajuste logarítmico da razão de umidade RM vs. t, para diferentes temperaturas

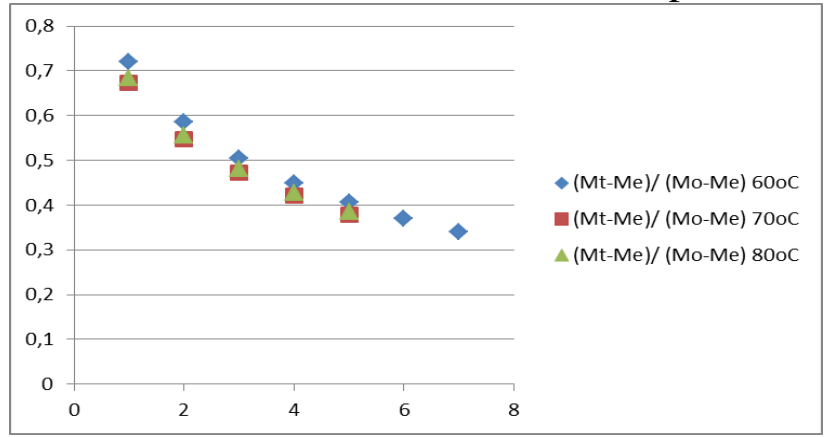


O ajuste logarítmico das Figuras 5 e $6\left(y=a^{*} \ln (t)+b\right)$, retirando a leitura para $\mathrm{t}=0$, conduziram aos seguintes parâmetros, respectivamente:

Tabela 1: resumo de parâmetros calculados para os ajustes logarítmicos de Mt e RM

\begin{tabular}{|c|c|c|c|c|}
\hline temperatura & $\mathbf{a 1}$ & $\mathbf{b 1}$ & $\mathbf{a 2}$ & $\mathbf{b 2}$ \\
\hline $60 \mathrm{oC}$ & $-0,061$ & 4,9183 & $-0,195$ & 0,7199 \\
\hline $70 \mathrm{oC}$ & $-0,061$ & 4,9039 & $-0,128$ & 0,4724 \\
\hline $80 \mathrm{oC}$ & $-0,064$ & 4,9243 & $-0,127$ & 0,4684 \\
\hline
\end{tabular}

\section{Considerações Finais}

A aplicação da tecnologia de secagem consiste na aplicação de calor que visa diminuir a umidade da matéria - prima antes da estocagem.

Este trabalho se propôs analisar a dependência da temperatura dos efeitos deletérios do aumento da temperatura.

Analisados os parâmetros obtidos mediante um ajuste logarítmico, o comportamento exibido por estes foi pouco relacionado com a mudança de temperatura.

$\mathrm{Na}$ modelagem logarítmica, apenas o parâmetro b2 apresenta uma pequena relação, mas somente para dois valores de temperatura $\left(60^{\circ} \mathrm{C}\right.$ e as outras duas temperaturas). Esta pouca dependência da temperatura torna menos interessante a aplicação do modelo de Arrhenius e isto converge com a teoria, porque este modelo foi proposto para reações e não operações, com uma multiplicidade de efeitos concorrendo.

A técnica de desidratação dos alimentos tem a finalidade de aumentar o tempo de conservação em relação aos produtos in natura. Este procedimento contribui com concentração de sabor e do valor nutritivo, além de apresentar facilidade de transporte e de manipulação no preparo dos produtos. Escolheram-se temperaturas moderadas para que o tratamento térmico não fosse demasiado severo em termos de temperatura, pois os nutrientes do produto podem ser afetados.

\section{REFERENCIAS}

FERNANDO, J. A. K. M.; AMARASINGHE, A. D. U. S.. Drying kinetics and mathematical modeling of hot air drying of coconut coir pith. SpringerPlus 5:807 (12pp.). Disponível em https://www.ncbi.nlm.nih.gov/pubmed/27390647. Acesso em 01.set.2018. 2016.

MENEZES, M. L.; STROHER, A. P.; PEREIRA, N. C.; BARROS, S. T. D. Análise da cinética e ajustes de modelos matemáticos aos dados de secagem do bagaço do maracujá-amarelo. Engevista, v.15, n.2, p.176-186, 2013.

MOCELIN, B.; OLIVEIRA JR., D.L.; CHIELlE, D. P.; TANABE, E. H.; BERTUOL, D. A.; SCHWAAB, M.; MEILI, L. Mathematical modeling of thin layer drying of papaya seeds in a tunnel dryer using particle swarm optimization method. Particulate Science and Technology, v.32. p. 123-130. 2014.

NOBLICK, L. R.; Palmeiras das caatingas da Bahia e as potencialidades econômicas. Simpósio sobre a Caatinga e sua Exploração Racional. EMBRAPA, Brasília, 1986.

SANTOS, J. A. R. Avaliação das propriedades físico-químicas, fluidodinâmicas, e oxidativas do biodiesel de licuri (syagrus coronata) e das blendas (licuri/soja). 2011. 26p. Dissertação (Programa de Pós-graduação em Química) - Departamento de Química, Universidade Federal da Paraíba. João Pessoa. Paraíba. 2011. 